\title{
O humor no ensino de línguas
}

\author{
Humor in language teaching \\ Leila Minatti Andrade \\ Fábio José Rauen \\ Universidade do Sul de Santa Catarina - Florianópolis, SC, Brasil
}

$\diamond$

\begin{abstract}
Resumo: Neste artigo, defendemos que o humor, especificamente em piadas, facilita o ensino da língua espanhola para estudantes brasileiros. Para tanto, apresentamos argumentos em favor da importância da utilização do humor para o ensino e a aprendizagem; mostramos como a teoria da relevância (SPERBER; WILSON, 1986, 1995) nos auxilia a compreender como as pessoas compreendem piadas; argumentamos que o docente deve prever possíveis traduções feitas pelos alunos para utilizar piadas em sala de aula apropriadamente; e, por fim, analisamos três piadas baseando-nos na classificação de Yus (2010). Concluímos que piadas transferíveis têm mais chances de serem compreendidas pelos estudantes, quando comparadas com piadas substituíveis e desafiadoras.
\end{abstract}

Palavras chave: Humor; Piada; Ensino de língua espanhola; Teoria da relevância

\begin{abstract}
In this article, we argue that humor, namely in jokes, helps teaching Spanish to Brazilian students. Therefore, we show some arguments establishing how humor is important for teaching and learning. Then, we show how relevance theory (SPERBER; WILSON, 1986, 1995) can help us to understand how people understand jokes. Next, we argue that the teacher must to anticipate possible student's translations in order to use jokes appropriately in class. Finally, we analyze three jokes based on the Yus' (2010) classification. We conclude that the students will comprehend more easily transferable jokes than replaceable and the challenging ones.
\end{abstract}

Keywords: Humor; Joke; Spanish teaching; Relevance theory

\section{Introdução}

A aprendizagem de uma língua estrangeira pode provocar ansiedade no aluno, levando-o a sentir-se inibido e com medo o que dificulta a internalização e reprodução do idioma. A utilização do humor por parte do educador pode facilitar a aprendizagem, especialmente porque o humor pode levar à diminuição desse nível de estresse. Quando o aluno é exposto a textos humorísticos, sua meta em foreground ${ }^{1}$ tende a ser o riso, de modo que a aprendizagem da língua estrangeira fica implícita/ inconsciente em background. Posto isso, o aluno se sente supostamente menos pressionado e mais relaxado. Nesse caso, a aprendizagem é uma consequência e não a principal preocupação. Ademais, o estímulo emocional gerado pelo humor contribui para a memorização dos conteúdos e,

\footnotetext{
1 Foreground é um termo utilizado para designar processos que estão sujeitos à interação direta do usuário. Diferencia-se, portanto, de processos em background, que ocorrem sem a interação direta do usuário.
}

consequentemente, facilita a aprendizagem, já que está diretamente ligada à memória (BARRIENTOS, 2013).

Além de o humor ajudar a criar um ambiente positivo e relaxado na sala de aula, argumentamos que a utilização do gênero piada no ensino do espanhol para brasileiros facilita a apresentação de língua autêntica, normalmente de registro coloquial ou familiar, em contextos comunicativos reais. $\mathrm{O}$ material humorístico existente nas piadas é uma das representações mais próximas do cotidiano de uma comunidade, de suas inquietações, pensamentos, caráter e modo de se expressar. Por isso, é preciso considerar que os textos de humor não se resumem a conteúdos linguísticos, mas incluem aspectos culturais, que sempre devem ser levados em conta pela diversidade de possiblidades que nos oferecem. O humor, portanto, está estreitamente ligado à cultura e, por meio de sua utilização, podemos introduzir diferentes elementos culturais dos países falantes da língua estrangeira. 
Este artigo será subdivido em cinco seções: na primeira, apresentaremos alguns argumentos que comprovam como o humor é importante para o ensino e aprendizagem; na segunda, mostraremos a importância da utilização da teoria da relevância na compreensão de piadas; na terceira, discorreremos sobre a tradução e o humor, na quarta, analisaremos três piadas conforme a classificação de YUS (2010); e, na última seção, apresentaremos nossas considerações finais.

\section{Humor e ensino}

Conforme Damasio (2001), as emoções desempenham papel fundamental na cognição. Apesar de não serem atos racionais, são as emoções que, mediadas pelos sentimentos, desencadeiam o processo cognitivo.

Entendemos que o riso gera emoções positivas, que aumenta a flexibilidade e a amplitude da cognição e do comportamento, além de ser expressão de saúde (FREDRICKSON, 2001). Fredrickson desenvolveu uma teoria, dentro do campo da psicologia, sobre o efeito benéfico das emoções positivas, que ficou conhecida como broaden-and-build theory (teoria de ampliação e construção). Segundo esse modelo, as emoções positivas permitem ampliar o repertório de pensamentos e ações do indivíduo e fomentar a construção de recursos para o futuro. De acordo com os experimentos da autora, depois de rir, tendemos a ser mais criativos, tomamos melhores decisões, somos mais generosos e nos aproximamos mais dos outros.

Entendemos, portanto, que fatores emocionais como ansiedade, medo, falta de motivação têm relação com a facilidade/dificuldade de aprendizagem. Quanto mais tenso, nervoso, desmotivado e com medo o aluno estiver, mais dificuldade terá em assimilar os conteúdos repassados. Em contrapartida, quanto mais se sentir relaxado, motivado, tranquilo, maior facilidade terá em adquirir conhecimentos novos. Isso sugere que estímulos humorísticos, ao desencadear emoções positivas, contribuem para criar ambientes de aprendizagem que facilitam a internalização dos conteúdos.

Além de o humor criar um clima motivador e propício para a aprendizagem, ele também favorece a memorização dos conteúdos. Estudos de Johnson, Hartney, Morgan (1983); Forgas (1987); Schimidt (1994); Gleitman (1999), Ellis e Morre (1999); Izquierdo (2009); Kandel (2009); Ynfante (2012); Barrientos (2013) Brains (2015) entre outros sugerem o grande valor mnemotécnico ${ }^{2}$ do humor. Para eles, os elementos humorísticos usados nas

\footnotetext{
2 Segundo a literatura sobre a epistemologia da memória, a palavra 'mnemônica' vem do grego 'mnese' que significa memorizar e capacidade de lembrar. Portanto técnicas mnemônicas ou mnemotécnicas consistem de estratégias para melhorar a retenção da informação.
}

aulas, ao suscitarem o riso, são mais memorizados do que aqueles apresentados de modo mais linear. Desse modo, as emoções contribuem para o processo de aprendizagem, já que são elementos importantes para a fixação da memória.

Todavia, por que memorizamos certas informações e descartamos outras? Defendemos que estímulos emocionais coadjuvantes facilitam a memorização. Desse modo, vamos nos lembrar de situações que nos deixaram muito tristes ou muito felizes, das coisas que nos fizeram rir, nos deixaram nervosos, nos entristeceram, ou seja, lembraremos daquilo que nos despertou emoções. As demais situações serão facilmente esquecidas. Sarmiento et al. (2007) afirmam que os fatores emocionais estão relacionados com a memória de longo prazo, por conseguinte, com a aprendizagem, pois interiorizamos um conhecimento quando conseguimos guardá-lo na memória de longo prazo.

Argumentamos que o professor, quando consegue relacionar o conteúdo com uma situação humorística, proporciona a seu aluno a experiência gratificante do riso. Sendo assim, o aluno não está somente recebendo um conteúdo, mas também experimentando o prazer do riso que está associado com esse conteúdo. Cada vez que um aluno ri, recebe ao mesmo tempo um input linguístico, e as possibilidades de que os estudantes se lembrem desse input aumentam consideravelmente, pois "o riso dispara a produção de catecolaminas (adrenalina e noradrenalina) ${ }^{3}$, hormônios que facilitam a retenção na memória de longo prazo" (NARVÁEZ, SOLÍS, 2009, p. 31, tradução nossa).

Como podemos constatar, memória e aprendizagem estão diretamente relacionadas, pois na aprendizagem adquirimos novos conhecimentos e na memória retemos os conhecimentos adquiridos. Se não houvesse memória, os processos de aprendizagem estariam sempre se iniciando. Em função disso, é necessário encontrarmos formas de ensinar que facilitem a memorização e, consequentemente, a aprendizagem. Uma maneira que nos parece adequada é trabalhar com a emoção gerada a partir dos textos de humor.

Apesar de existirem diversas pesquisas que comprovam os benefícios que o texto de humor traz à aprendizagem, infelizmente, eles praticamente não aparecem nos manuais de ensino de língua espanhola. Quando aparecem, na maioria das vezes, são apenas uma distração ou entretenimento. Em geral, os alunos podem ler, se desejarem, e seu emprego em sala de aula fica a critério do professor. Há também situações nas quais se coloca um texto de humor cujo grau de processamento é

\footnotetext{
As catecolaminas são importantes neurotransmissores e hormônios circulantes. As mais abundantes são a adrenalina, noradrenalina e dopamina. Como hormônios, são libertadas pela glândula suprarrenal em situações que envolvem emoções como o estresse. Esses hormônios facilitam a retenção na memória de longo prazo. (BENEDICT, 1987).
} 
tão alto, que o aluno deve buscar as palavras no dicionário e fazer uma análise do texto para compreendê-lo. Nesse caso, perde-se o objetivo principal do texto de humor - o riso. Noutros termos, o custo de processamento é tão alto que os efeitos cognitivos acabam não compensando.

O gênero piada é praticamente inexistente nos livros didáticos, talvez pela dificuldade de selecionar uma piada adequada para se trabalhar com os alunos. Para que uma piada funcione, ela deve ser escolhida de tal modo que as dificuldades léxicas, fonéticas, gramaticais e culturais não impeçam seu rápido processamento. Caso contrário, o estudante não poderá resolver espontaneamente o mistério do chiste, ou seja, não poderá resolver a incongruência, e a magia do humor não chegará a sua mente. Por outro lado, a inserção de piadas que o estudante consiga entender rapidamente pode criar um clima agradável de integração, que é promotor da aprendizagem.

Fernández (1999), em artigo sobre a utilização de textos de humor no ensino do espanhol para estrangeiros, concluiu que aplicar o humor no ensino do espanhol pode ser sumamente frutífero apesar de certas dificuldades. Segundo a autora, para que a utilização de textos com humor surtisse o efeito esperado, deveriam ser cumpridas várias condições:

\begin{abstract}
Que seu conteúdo linguístico seja facilmente compreensível pelos alunos, com o objetivo de que surta efeito sua função humorística de modo espontâneo; que não se incluam como um mero acréscimo ou como mais um texto de compreensão escrita; que se vinculem diretamente aos objetivos linguísticos que estamos apresentando em sala de aula (FERNÁNDEZ, 1999, p. 85, tradução nossa).
\end{abstract}

Em síntese, os resultados de todos esses estudos fortalecem nosso argumento inicial de que o humor facilita o processo de ensino-aprendizagem, exceto em casos de sarcasmos e de humor negativo. O humor positivo cria um clima agradável, reduzindo o estresse e a tensão; estabelece uma relação mais próxima entre professores e alunos; desperta o interesse dos alunos e os motiva; traz benefícios cognitivos; e, portanto, contribui com os resultados acadêmicos. Para isso, o material deve estar muito bem preparado e relacionado com conteúdo estudado para ser atrativo e interessante. Isso sugere que, quando bem empregado, ou seja, em situações que ilustram os pontos principais de um conteúdo, o humor é um facilitador da aprendizagem.

O humor é bem-vindo em todas as situações, faz bem para a saúde e para os relacionamentos. Concordamos com Sánchez (2000, p. 8, tradução nossa) quando diz que "tudo com humor é mais tolerável; se o humor está na vida cotidiana, por que vamos excluí-lo da sala de aula? Sua presença nas aulas é importante, desejável, útil e benéfica". Uma aula, na qual o riso e as emoções positivas proliferam, é um lugar em que é agradável estar, aprender e prestar atenção, ou, no caso do professor, de trabalhar e ensinar (BARRIENTOS, 2013).

Conforme Fernández (1999), compreender uma piada requer que nossa mente trabalhe de um modo mais global do que o habitual, que funcione de um modo holístico. Ao receber um discurso linear, sem elementos ambíguos ou figuras retóricas, a informação verbal é processada quase que totalmente pelo hemisfério esquerdo do cérebro. No entanto, quando há algo que faz com que reestruturemos a informação que recebemos para que possamos compreendê-la, desfazendo ambiguidades, entra também em jogo o hemisfério direito (onde estão lateralizadas tarefas mais holísticas). Com os dois hemisférios em funcionamento, a possibilidade de que recordemos o conteúdo apresentado é muito maior.

Apesar de os textos humorísticos serem uma ferramenta bastante útil, o humor não pode ser visto como um fim por si só. Quando o professor utiliza o humor como recurso didático, sua meta deve ser a de ensinar através do humor. $\mathrm{O}$ riso é um dos seus objetivos, mas não o único. O humor pelo humor pode não trazer contribuições para o ensino. Pensamos que o professor deve utilizar o componente humorístico para trabalhar diferentes conteúdos gramaticais, fonéticos, linguísticos, culturais, etc. Por conseguinte, é essencial que o docente tenha bastante clareza sobre os objetivos que está trabalhando aquele determinado texto de humor.

Vale finalizar dizendo que a utilização do humor é válida no ensino de diferentes disciplinas. Todavia, quando o objetivo é ensinar uma língua estrangeira através de textos de humor, há certa dificuldade tanto para o professor (por exemplo, na seleção do material adequado), como para o aluno (especialmente, na compreensão do humor). Para que as piadas, por exemplo, despertem interesse e cumpram seu papel, o professor deve ter em mente o ambiente cognitivo de seus alunos, considerando fatores como a idade, crenças religiosas, nível social. Isso põe em evidência que a piada deve ter um conteúdo linguístico, extralinguístico, cultural e pragmático que seja facilmente compreensível por todos os alunos. Caso contrário, ela não surtirá os efeitos esperados e será somente mais um texto para se trabalhar a compreensão verbal. Caso o aluno não entenda a piada que está sendo trabalhado, ou, por alguma razão, não goste dela, por exemplo, a utilização desse gênero textual pode gerar efeito contrário, ou seja, um clima tenso, desagradável, constrangedor que dificulta a aprendizagem.

Argumentamos que a teoria da relevância pode auxiliar nesse processo de escolha de materiais relevantes para o ensino. Por meio dessa teoria, o professor pode prever as possíveis inferências e conclusões que os alunos farão e, a partir disso, optar por materiais que gerem menos custo de processamento e maiores efeitos cognitivos. 


\section{Teoria da Relevância e Humor}

A teoria da relevância proposta por Sperber e Wilson (1986, 1995), que é uma teoria de viés pragmáticocognitivo da comunicação, vem sendo aplicada com sucesso em diferentes gêneros textuais, entre os quais, os humorísticos ${ }^{4}$. Conforme Yus, "a previsibilidade cuja interpretação é consistente com o princípio de relevância pode ser útil para criadores de textos humorísticos" (1998, p. 332, tradução nossa).

A teoria da relevância é vista como um processo ostensivo-inferencial, ou seja: o comunicador produz um estímulo e faz com que seja mutuamente manifesto intenção comunicativa - à sua audiência que ele pretende tornar manifesto um conjunto de suposições - intenção informativa. Uma vez que a intenção informativa do comunicador é reconhecida pelo público, a comunicação é bem-sucedida. Muitas vezes, ocorre de o público perceber a intenção comunicativa, mas não reconhecer a intenção informativa do falante, pois a comunicação só será bem-sucedida quando o contexto mobilizado na mente da audiência corresponder a um contexto ${ }^{5}$ previsto pelo comunicador.

Entendemos que o ambiente cognitivo mutuamente manifesto é a condição prévia para a realização do humor. O professor deve estar ciente desta condição ao selecionar piadas para trabalhar em sala de aula. Ele deve estar consciente de que o sucesso da utilização de uma determinada piada depende do contexto cognitivo partilhado entre o docente e seus alunos, pois só assim será possível obter os efeitos humorísticos esperados.

Outro ponto importante a ser levado em consideração é que o aluno, ao ouvir/ler uma piada, sempre terá a expectativa de obter a relevância ótima, ou seja, compreender os estímulos com menor esforço e com os maiores efeitos contextuais possíveis. Sendo assim, de nada adianta se trabalhar uma piada com um alto custo de processamento, pois ela não será estimulante para $\mathrm{o}$ aluno.

Conforme Curcó (1995), a maioria dos estudiosos do humor (por exemplo, Raskin 1979, Pretorius 1990, Attardo 1994) analisa os textos humorísticos para fazer uma descrição adequada e explicar o humor verbal. A autora, entretanto, sugere que precisamos analisar como os ouvintes interpretam o humor. Para dar conta disso, temos que focar nos processos mentais mobilizados pelo ouvinte durante sua interpretação.

\footnotetext{
4 É expressiva a quantidade de textos conectando relevância a textos humorísticos no site Relevance Theory Online Bibliographic Service de Yus $<$ https://sites.google.com/site/franciscoyus/home>.

5 Lembrando que o contexto na teoria da relevância é dinâmico e é estabelecido e desenvolvido pelos interlocutores no decurso da interação com o objetivo de selecionar as interpretações mais adequadas.
}

Curcó (1995) mostra que o humor pode ser gerado pela oposição de dois conteúdos proposicionais discrepantes. O ouvinte, depois de haver processado o material disponível no contexto mais acessível, encontra um efeito contraditório e recua. Ou seja, o ouvinte, que é levado a esperar a relevância em uma determinada direção, descobre de repente algo imprevisível e tem de refazer o processo e refutar a relevância inicial para procurar um novo caminho.

Vamos mostrar como isso ocorre utilizando o primeiro enunciado da piada seguinte:

\section{Piada 1:}

(1a) Un ladrón ha entrado en mi casa para buscar dinero esta noche. Me levanté y decidí ayudarle. ${ }^{6}$

Para processar esse enunciado, o ouvinte fará algumas hipóteses antecipatórias, ou seja, ele irá processar alguns dos conceitos codificados antes de outros. Essas hipóteses referem-se à estrutura lógico-sintática do enunciado. A forma lógico-sintática do primeiro enunciado (1b) pode ser representada como em (1c):

(1b) Ha entrado un ladrón en mi casa para buscar dinero esta noche.

(1c) [ALGUÉM [Un ladrón]] [FEZ ALGO [ha entrado]] [EM UM LUGAR [en mi casa]] [PARA ALGUMA FINALIDADE [buscar dinero]] [EM ALGUM TEMPO [esta noche]]

Quando o interlocutor ouve "Un ladrón", ele terá que lhe atribuir uma categoria sintática e fazer hipóteses antecipatórias (1d):

\section{(1d) Un ladrón hizo algo.}

O ouvinte, após lançar essa hipótese, antecipa que o ladrão deve ter feito algo. Em seguida, ele ouve "Un ladrón ha entrado". Então, ele pressupõe que o restante do enunciado irá responder a perguntas como "Onde?", "Quando?", "Como?" e assim por diante. Nesse caso, ocorre um conjunto de hipóteses de antecipação. As hipóteses corretas são logicamente relacionadas umas às outras, e podem ser colocadas em uma escala na qual cada membro analiticamente implica o seu membro imediatamente anterior. Vejamos a seguir a escala de hipóteses antecipatórias para o exemplo:

(1e) Un ladrón hizo algo

¿Que hizo el ladrón?

\footnotetext{
6 Disponível em: $<$ http://www.megachistes.com/humor/ironizar $>$. Acesso em: 4 jan. 2016.
} 
(1f) Un ladrón ha entrado?

¿Dónde ha entrado un ladrón?

(1g) Un ladrón ha entrado a mi casa.

¿Para qué ha entrado un ladrón a su casa?

(1h) Un ladrón ha entrado a mi casa para buscar dinero. ¿Cuándo que ha entrado un ladrón a su casa para buscar dinero?

(1i) Un ladrón ha entrado a mi casa para buscar dinero esta noche.

Um ouvinte pode produzir um número indefinido de hipóteses, mas irá formular as que lhe parecem mais relevantes. Evidentemente, nem todas as hipóteses antecipatórias são recuperadas ao mesmo tempo. No decorrer do processo de compreensão, ele irá descartar umas e fortalecer outras, de acordo com o que lhe é mais relevante. Desse modo, o princípio de relevância auxilia na percepção da incongruência ${ }^{7}$, que é fundamental para o entendimento do humor verbal.

Podemos perceber, nessa piada, que há certa ironia na incongruência gerada pelo punchline $e^{8}$ " "Me levanté y decidí ayudarle", pois as suposições mais relevantes que o ouvinte faria nessas circunstâncias seriam:

$\mathrm{S}_{1}$ - O dono da casa ficou com medo do ladrão;

$\mathrm{S}_{2}-\mathrm{O}$ dono da casa tentou agredir o bandido;

$\mathrm{S}_{3}-\mathrm{O}$ dono da casa tentou fugir;

$\mathrm{S}_{4}-\mathrm{O}$ dono da casa chamou a polícia.

No entanto, o dono da casa, ironizando o bandido, diz que vai ajudá-lo a procurar dinheiro. Conforme Grice (1975), a ironia implica o oposto da proposição expressa no enunciado e desrespeita a máxima de veracidade. Curcó (1995) discorda e propõe que a ironia é um tipo de incongruência que não emerge de uma interpretação oposta, mas é uma parte central do processo de interpretação. O punchline da piada, "Me levanté y decidí ayudarle", não desrespeita a máxima de veracidade, muito provavelmente porque ela sugere que o dono da casa também não tem dinheiro. Portanto, a ironia nessa piada é uma parte central do processo de interpretação. Para compreendermos a piada, não substituímos o significado "literal" por seu oposto, mas procuramos um sentido relevante para sua incongruência.

Como vimos, o processo de compreensão de uma piada não é algo simples, mas a Teoria da Relevância

\footnotetext{
7 Incongruência na piada é quando o leitor cria uma expectativa sobre um determinado evento e se depara com uma situação incongruente com relação à expectativa que ele mantinha

8 Por Punchline, de punch, significando soco, e line, significando linha, literalmente, linha de soco, define-se a parte da piada, geralmente próxima de seu fim, onde ocorre uma ruptura com as informações anteriores e se instala a incoerência predisponente ao riso.
}

pode auxiliar-nos na escolha de piadas que possam ser trabalhadas em sala de aula, ajudando-nos a prever as possíveis suposições que os alunos farão e também as possíveis traduções feitas por eles. O nosso objetivo não é traduzir as piadas, mas fazer com que o aluno as entenda na língua estrangeira. No entanto, alunos que se encontram em fase inicial ${ }^{9}$ do conhecimento tendem a passar inconscientemente pela tradução para interpretar um texto em língua estrangeira. Sendo assim, para que o docente selecione as melhores piadas para serem trabalhadas em sala de aula, ele também deve tentar prever as possíveis traduções dos alunos.

\section{Tradução e humor}

O esforço mental que um aluno em fase inicial de aprendizagem deve fazer para compreender uma piada em língua estrangeira é muito grande. Em geral, para conseguir compreendê-la, ele tende a traduzi-la. Conforme Yus (2010), compreender uma piada exige mais esforço mental que compreender outro gênero textual, pois em uma comunicação humorística o falante acaba se envolvendo em tipo de intencionalidade encoberta que não está diretamente manifesta em prol da geração de efeitos humorísticos. Para o autor, uma das consequências dessa intencionalidade encoberta é que muitas vezes a interpretação mais relevante, a que o ouvinte tem o direito de escolher, devido a um equilíbrio ideal de efeitos cognitivos e esforço mental, acaba por ser rejeitada e substituída por outra menos provável, embora supostamente ela seja a interpretação correta. Deste modo, as piadas exigem um grande esforço mental, que só pode ser compensado pelos efeitos humorísticos prometidos. Todavia, a satisfação obtida da interpretação da piada na forma desses efeitos nunca é garantida, pois, além de depender de vários fatores já mencionados neste artigo, nem sempre o que gera riso em uma língua gerará riso em outra.

Se aprender uma língua estrangeira e compreender o humor são atividades complexas em si mesmas, tome-se o caso de traduzir o humor. Entendemos que o humor faz parte da cultura, que faz parte da língua. Rimos de diferentes temas, por diferentes razões. Faz parte de nossa cultura rir de determinadas situações. E parte de outras culturas rir de outras situações. Não há, portanto, como fazer uma boa tradução se não tivermos conhecimento das situações que causam riso na língua meta.

Yus (2010), em seu artigo Relevance, humour and translation, traduz piadas do inglês para o espanhol a

\footnotetext{
9 Os alunos a que nos referimos estão no ensino médio. Ao se formarem, eles terão tido um total de 160 horas/aula de língua espanhola. Considero que a grande maioria terá um nível básico de conhecimento do idioma. Sendo assim, dificilmente eles entenderão a piada espontaneamente sem passar pelo processo de tradução.
} 
partir de uma perspectiva pragmática cognitiva. Para ele, a tradução pode ser explicada como uma atividade de preenchimento de lacunas inferenciais, nas quais o tradutor tem de inferir a interpretação pretendida e fazer previsões entre a língua fonte e público da língua alvo. Nesse caso, o tradutor tem uma tarefa complicada na tradução do humor, já que agora existem lacunas (a) entre a interpretação pretendida pelo autor da língua fonte e o texto humorístico da língua fonte codificado; (b) entre a piada no idioma original e a interpretação do tradutor; (c) entre a interpretação do tradutor e a língua alvo do texto humorístico do tradutor e, finalmente, e (d) entre a piada codificada na língua alvo e a interpretação selecionada pelo público da língua alvo. Todas essas lacunas devem ser semelhantes para que os efeitos humorísticos entre o público da língua fonte e o público de língua alvo sejam os mesmos. $\mathrm{O}$ tradutor tem a presunção de que sua versão se assemelhe a do texto original.

$\mathrm{O}$ autor propõe um gráfico de piadas baseando-se no tipo de procedimento inferencial que se espera que os ouvintes/leitores percorram quando interpretam uma piada (Gráfico 1).
Yus (2010) classifica as piadas em transferíveis, substituíveis e desafiadoras. As piadas transferíveis são aquelas fáceis de serem traduzidas. São piadas com estereótipos sociais interculturalmente válidos, formas paralelas de codificação da informação e estratégias linguísticas para a geração de humor que podem ser encontrados em ambas as línguas. Sendo assim, elas podem ser traduzidas literalmente sem perda do humor, do conteúdo ou do significado.

No exemplo (2), a seguir, temos um caso de piada transferível:

\section{Piada 2:}

Era una señora tan fea, pero tan fea, que cuando fue a un concurso de feos le dijeron:

- Lo sentimos, no aceptamos profesionales. ${ }^{10}$

Consideramos essa piada transferível, pois facilmente seria traduzida e, provavelmente, causaria humor em qualquer idioma. Não há neste texto jogos linguísticos, nem estereótipos culturais.

Gráfico 1. Piadas de Yus (2010)

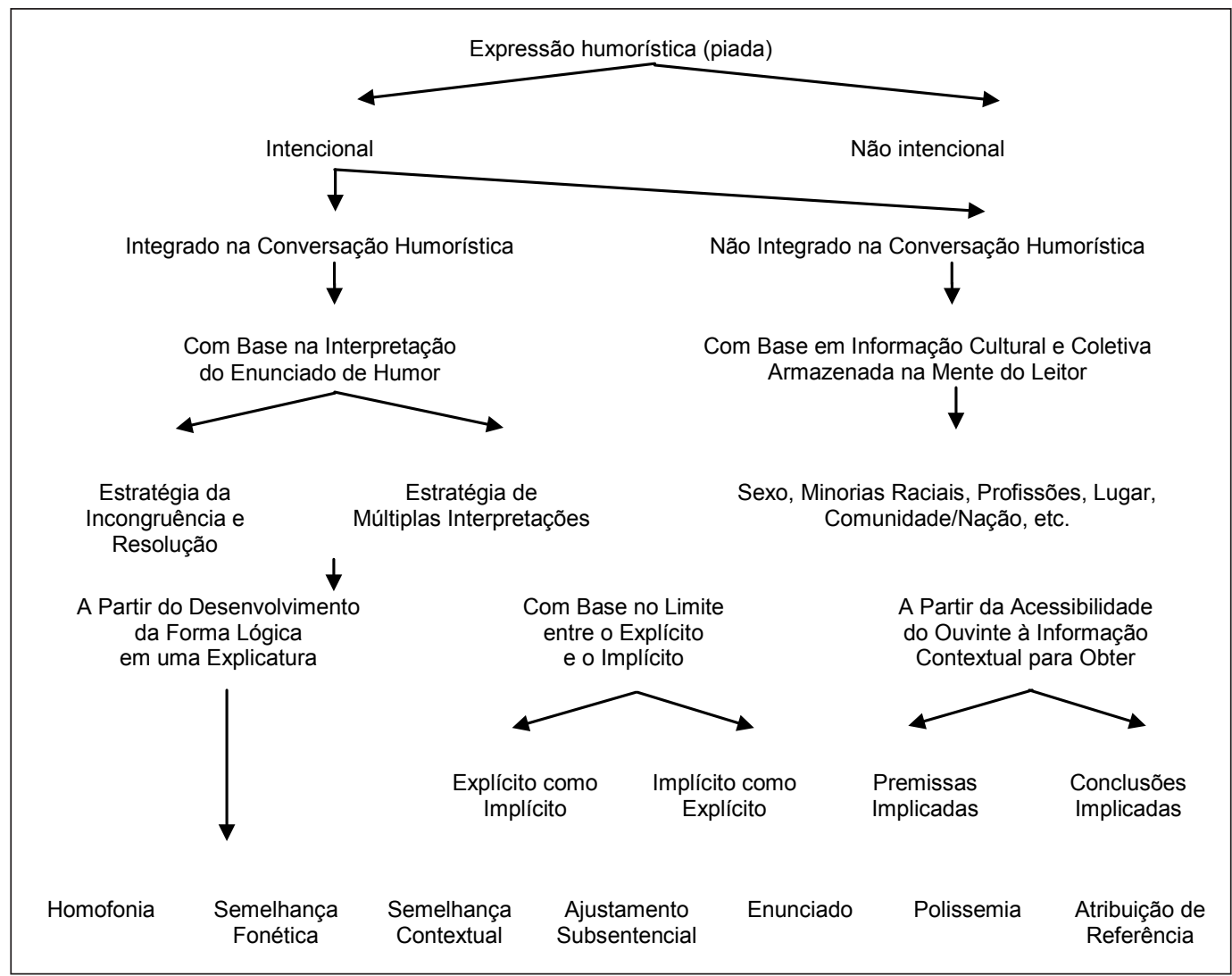

Fonte: Yus (2010, p. 2, tradução nossa)

\footnotetext{
${ }^{10}$ Disponível em: $<$ http://www.1000chistes.com/chistes/feos>. Acesso em:

4 jan. 2016.
} 
As piadas substituíveis são as que envolvem referentes culturais que podem ser encontrados, com maior ou menor similaridade, em culturas de origem e de destino. Nesses casos, embora as fontes linguísticas de humor não sejam as mesmas, as alternativas podem ser encontradas na língua-alvo alcançando saldos semelhantes de efeitos cognitivos e esforço mental. Observemos a piada (3) a seguir (FERNANDEZ, 2012):

\section{Piada 3.}

Un hombre que iba manejando su automóvil llega hasta las puertas del Congreso y se estaciona. El policía de tránsito llega inmediatamente y le dice:

- Oiga, no estacione su carro ahí que van a salir los diputados.

El hombre dice tranquilamente:

- No se preocupe, tiene alarma.

Essa é uma piada mexicana e nos mostra como os mexicanos veem o poder legislativo de seu país (FERNÁNDEZ, 2012, p. 8). A polícia convida o motorista que retire seu carro, pois atrapalhará a saída dos deputados, mas o condutor entende a mensagem como uma advertência de que seu carro corre perigo de ser roubado por membros do poder legislativo, e responde que seu carro tem alarme. É uma piada baseada em um estereótipo cultural concreto: para os mexicanos, políticos são ladrões. É considerada uma piada substituível, pois caso a língua alvo não reconhecesse os políticos como ladrões, o termo 'diputados' poderia ser substituído por outro, procurando manter saldos semelhantes de efeitos e esforços cognitivos.

As piadas desafiadoras são as que representam problemas reais para a tradução, devido a referências intraculturais muito específicas ou a recursos linguísticos (homônimos, aliterações, rimas, polissemias) que não têm contrapartida na língua-alvo.

Vejamos a piada 4 (RODRÍGUEZ, 2002):

\section{Piada 4:}

Pepito fue a confesarse. Le pregunta el cura:

- ¿Pecas, hijo?

- ¡Hasta en el trasero padre!

A palavra 'pecas' em espanhol, tanto pode ser entendida como a segunda pessoa do presente do indicativo do verbo pecar - tú pecas -, como também pode ser entendida como "sardas". Aqui, por envolver uma situação de confissão, a interpretação mais relevante seria a do verbo pecar. No entanto, não é a interpretação escolhida pelo menino. É essa incongruência, ou seja, a incapacidade de o menino entender o sentido mais provável da palavra no discurso religioso, que gera o humor na piada. É considerada uma piada de desafio para o tradutor, pois envolve léxico e morfossintaxe. $\mathrm{O}$ tradutor, dependendo da língua alvo, deverá recriar a piada buscando manter os mesmos efeitos de humor.

O professor, portanto, ao selecionar piadas para trabalhar em sala de aula, terá de ter clareza sobre o ambiente cognitivo de seus alunos e também sobre seu objetivo em trabalhar determinada piada. Para isso, ele terá de prever quais as suposições que seus alunos farão sobre a piada trabalhada em sala de aula. Para prever as suposições, o professor também terá que prever as traduções que o aluno fará.

\section{Análise de piadas}

Considerando a classificação de Yus (2010), vamos apresentar a análise de três piadas: a primeira estará relacionada com a forma lógica ${ }^{11}$ e a explicatura ${ }^{12}$, ou seja, são as várias possibilidades que a forma lógica pode ser inferencialmente enriquecida e transformada em uma explicatura em um contexto específico, a segunda é uma piada cuja compreensão está entre a fronteira da comunicação explícita e implícita e a última, é uma piada cujo humor é baseado em um estereótipo cultural próprio.

$\mathrm{Na}$ piada 5, a seguir, o humor é baseado na inferência explícita do significado e é por atribuição de referência.

\section{Piada 5:}

Un niño entra a la iglesia y el cura le pregunta:

- ¿quieres ser cristiano?

Y el niño le contesta:

- No, quiero ser Mesi.

Nessa piada, ocorre uma confusão na atribuição de referência, porque o 'cura' (padre) quer saber se o menino quer ser 'cristiano' (cristão), no entanto o menino entende 'cristiano' como sendo o Cristiano Ronaldo, jogador do Real Madri, então responde que não quer ser Cristiano, mas quer ser Mesi, que é jogador do Barcelona. Essa piada envolve baixo custo de processamento para os alunos brasileiros e bons efeitos cognitivos; portanto, eles facilmente conseguiriam chegar ao riso. Porém, para conseguir entendê-la, o aluno não pode traduzi-la, mas interpretá-la na língua estrangeira. Caso os alunos não tivessem em seu conhecimento enciclopédico que Cristiano Ronaldo é um excelente jogador do Real Madri e Mesi, do Barcelona, seria impossível que eles

\footnotetext{
11 A forma lógica é um conjunto de representações semânticas sem valor de verdade e se relaciona com o processo de decodificação.

12 A explicatura é desenvolvida por meio de processos inferenciais que completam a informação explícita.
} 
desvendassem o mistério da piada. Como o Brasil é 'o país do futebol', pressupomos que a grande maioria dos alunos, principalmente adolescentes e adultos, fariam as inferências adequadas. No entanto, se essa piada fosse contada em países que não se interessam por futebol, eles não conseguiriam entender a incongruência da piada e, portanto, não ririam. Sendo assim, essa piada seria considerada desafiadora para o tradutor, já que apresenta um elemento cultural e um jogo fonético ao mesmo tempo. Além disso, aqui também ocorre um jogo léxicosemântico, já que 'Cristiano' e 'cristiano', embora sejam foneticamente idênticos, não indicam o mesmo referente.

Entendemos que essa piada pode ser utilizada em sala de aula com tranquilidade, principalmente quando o tema da aula for futebol, que é um assunto que desperta grande interesse não só dos brasileiros, como também de diversos povos falantes do espanhol. Todavia, há que se tomar cuidado que essa piada não é atemporal. Não há garantias de que ela sirva daqui a algumas décadas, por exemplo.

Na piada 6, a seguir, a estratégia utilizada foi a de jogar com uma interpretação explícita acessível de um enunciado e substituí-la com uma interpretação implícita menos provável.

\section{Piada 6:}

- Ayer me llamó Laura a casa diciéndome: "Ven a casa, no hay nadie".

- ¿Y qué? Cuenta, cuenta...

- Pues que efectivamente cuando llegué a su casa no había nadie...

Nessa piada, há dois amigos conversando e um diz ao outro que Laura lhe telefonou convidando-o para ir a sua casa, dizendo-lhe que não tinha ninguém. A inferência mais provável de se fazer quando Laura diz que não há ninguém na casa, seria a interpretação implícita de que ela está sozinha, ou seja, é a expressão não literal que costuma ser a mais usual, pois já está consagrada pela língua. No entanto, essa primeira interpretação deve ser descartada ao final da piada, quando se descobre que é a interpretação explícita que deveria ser levada em conta, ou seja, deve-se tomar a frase "vem a casa, no hay nadie" no seu sentido literal.

Essa piada poderia ser trabalhada em sala de aula com jovens e adultos. Seria facilmente compreendida por um estudante brasileiro e, se ele partisse da língua materna para entendê-la, seria bem-sucedido, já que essa seria considerada uma piada transferível. Poderia ser utilizada para trabalhar o modo imperativo 'Ven', 'Cuenta'; a colocação pronominal 'me llamó', 'diciéndome', entre outras coisas.
O humor na piada 7, é baseado em um estereótipo cultural próprio:

\section{Piada 7}

Un argentinito le dice a su padre:

- Papá, papá... cuando crezca quiero ser como vos.

- El padre todo orgulloso le contesta:

- Y sí... no me sorprende... ¿pero por qué exactamente?

- ¡Para tener un hijo como yo!

Os efeitos de humor nessa piada são baseados em informações culturais, e ela é considerada substituível, pois poderíamos trocar o termo "argentinito" por outro mais acessível, se fosse o caso, para manter os mesmos efeitos de humor. Para que o estudante conseguisse fazer as inferências adequadas e, consequentemente, conseguisse resolver a incongruência para chegar ao riso, deveria fazer parte de seu ambiente cognitivo a soberba dos argentinos. Se o estudante não consegue acessar essa informação em seu conhecimento enciclopédico, ele não será capaz de interpretar adequadamente a piada $\mathrm{e}$, consequentemente, não rirá.

\section{Considerações finais}

O objetivo geral deste artigo foi o de mostrar que o humor, especificamente a piada, facilita o processo de ensino e aprendizagem da língua espanhola. Para dar conta do nosso objetivo, apresentamos argumentos que comprovam como o humor é importante para o ensino; mostramos que a utilização da teoria da relevância nos auxilia no processo de compreensão das piadas; explicamos que o docente também terá de prever as possíveis traduções feitas pelos alunos e, para finalizar, analisamos três piadas baseando-nos na classificação de YUS (2010), argumentando sobre as possibilidades de trabalhá-las ou não em sala de aula.

A partir de nosso estudo, podemos considerar que, de fato, a utilização da piada contribui para o ensino e aprendizagem da língua espanhola, mas, para isso, deve ser levado em conta o ambiente cognitivo dos alunos. A piada não deve ter um grau de processamento muito alto, caso contrário não será possível desvendar seu mistério e, com isso, fazer emergir o riso. Do ponto de vista prático, consideramos que as piadas transferíveis têm mais chances de serem compreendidas pelos estudantes, quando comparadas com piadas substituíveis e desafiadoras, já que os alunos tendem a partir da língua materna para compreender a língua estrangeira no nível inicial de aprendizagem. E, normalmente, quando se traduz uma piada transferível mantêm-se os mesmos efeitos de humor, o que não ocorre nos outros tipos de piada. 


\section{Referências}

ATTARDO, Salvatore. Linguistic theories of humor. New York: Mouton de Gruyter, 1994.

BAINS, Gurinder Singh. et al. Humor's Effect on Short-term Memory in Healthy and Diabetic Older Adults. Alternative therapies in health and medicine, v. 21, n. 3, p. 16-25, 2015. Disponível em: <http://acmem-logopedia.com/onewebmedia/ Humor_older_adults.pdf $>$. Acesso em: 22 fev. 2016

BARRIENTOS, Cecilia Verónica González. El humor como instrumento pedagógico, del curso de Licenciatura Hispánica con Mención en Literatura. 2013. 35 f.. Monografía (Graduação em Licenciatura en Lengua y Literatura Hispánica con Mención en Literatura) - Universidad de Chile, Santiago de Chile, 2013. Disponível em: < http://repositorio.uchile.cl/ handle/2250/113094>. Acesso em: 12 dez. 2015.

CURCÓ, Carmen. Some observations on the pragmatics of humorous interpretations. A relevance-theoretic approach. UCL Working Papers in Linguistics, v. 7, p. 27-47, 1995. Disponível em: <http://www.phon.ucl.ac.uk/publications/WPL/95papers/ CURCO.pdf $>$ Acesso em: 03 abr. 2015.

DAMASIO, Antonio. Fundamental Feelings. Nature, n. 413, p. 781, 2001 .

ELLIS, Henry C.; MOORE, Brent A. Mood and memory. In: DALGLEISH ,Tim; POWE,R Mick J. (Ed.). Handbook of cognition and emotion. New York: John Wiley \& Sons, 1999. p. 191-210.

FORGAS, Joseph; BOWER, Gordon. Mood effects on person perception judgments. J Pers Soc Psychol, Boulder, v. 53, p.53-60, 1987. Disponível em: <http://web.stanford. edu/ gbower/1987/Mood_effects_person_perception.pdf $>$. Acesso em: 3 nov. 2016.

FREDRICKSON, Barbara. The role of positive emotions in positive psychology: The broaden-and-build theory of positive emotions. American Psychologist, v. 56, p. 218-226, 2001

FERNÁNDEZ, Miguel Arroyo. ¿Caben los chistes en el aula? Algunos principios para la aplicación del humor en clase y para su integración en los materiales de ELE. In: CONGRESO INTERNACIONAL DE ASELE, X., 1999. Zaragoza. Anais eletrônicos. Zaragoza: Instituto Cervantes, 1999. p. 79-86. Disponível em: <http://cvc.cervantes.es/ ensenanza/biblioteca ele/asele/pdf/10/10 0077.pdf>. Acesso em: 3 abr. 2014.

FERNÁNDEZ, Iñigo. Los mexicanos somos... El chiste como autorepresentación y estereotipo del mexicano. Diacronie: Studi di Storia Contemporanea, Bologna, v. 1, n. 8. 2012. Disponível em: <https://diacronie.revues.org/2700?lang=es>. Acesso em: 14 dez. 2015.

GLEITMAN, Henry. Como as emoções influenciam a memória. Psicologia. 4. ed. Lisboa: Fundação Calouste Gulbenkian, 1999.

GRICE, Herbert Paul. Logic and conversation. In: COLE, M. Syntax and semantics, v. 3, Speech acts. New York: Academic Press, 1967/1975. Disponível em <http://www.ucl.ac.uk/ls/ studypacks/Grice-Logic.pdf>. Acesso em: 12 set. 2014.
YNFANTE, Freddy Antonio Gonzalez. El sentido del humor ¿es incompatible con la dirección escolar? Revista Didasc@ lia: Didáctica y Educación, v. 4, n. 1, p.181-188, 2012. Disponível em: <https://dialnet.unirioja.es/servlet/ articulo? codigo $=4233816>$. Acesso em: 10 mar. 2014.

IZQUIERDO, Ivan. Questões sobre memória. São Leopoldo: Unisinos, 2009.

JOHNSON, James; Petzel, Thomas; HARTNEY, Linda; MORGAN, Russel. Recall of importance ratings of completed and uncompleted tasks as a function of depression. Cognit Ther Res, v. 7, p. 51-56, 1983. Disponível em: <http://link.springer. com/article/10.1007\%2FBF01173423\#page-1>. Acesso em: 1 dez. 2014.

KANDEL, Eric Richard. Em busca da memória: o nascimento de uma nova ciência da mente. Trad. Rejane Rubino. São Paulo: Companhia das Letras, 2009. Disponível em: <http://www. companhiadasletras.com.br/trechos/12309.pdf> Acesso em: 5 out. 2015

NARVÁEZ Eduardo Jáuregui; SOLÍS, Jesús Damián Fernández. Risa y aprendizaje: el papel del humor en la labor docente. Revista Interuniversitaria de Formación del Profesorado, v. 66, p. 203-215, 2009.

PRETORIUS, Elizabeth. Humor as defeated discourse expectations. Humor, v. 3, n. 3, p. 259-276, 1990. Disponível em: <http://psycnet.apa.org/psycinfo/1992-30610-001>. Acesso em: 19 jul. 2014.

RASKIN, Victor. Semantic Mechanisms of humour. In: Annual Meeting of the Berkeley Linguistics Society. Dordrecht, p. 325335. 1979. Disponível em: <file:///D:/Downloads/2164-21291-PB.pdf> Acesso em: 9 nov. 2015.

RODRIGUEZ, Regina Amelia Darriba. Los aspectos lingüísticos del humor. In: CONGRESO BRASILEÑO DE HISPANISTAS, 2., 2002, São Paulo. Anais... Disponível em: $<$ http://www.proceedings.scielo.br/scielo.php?pid=MSC0000 $000012002000100051 \&$ script $=$ sci arttext\&tlng $=$ es $>$. Acesso em: 28 jan. 2016.

SÁNCHEZ, Miriam Sancho. El humor en la clase de español. Cuadernos Cervantes, n. 26, Madrid: ERL Ediciones, 2000. p. 8-10. Disponível em: <http://cvc.cervantes.es/ensenanza/ biblioteca ele/asele/pdf/16/16 0124.pdf>. Acesso em: 22 set. 2014.

SARMIENTO, Edward Leonel Prada. Emoção e Memória: inter-relações psicobiológicas. Brasília Médica, Brasília, v. 44, p. 24-39, 2007. Disponível em: <http://bases.bireme.br/ cgi-bin/wxislind.exe/iah/online/?IsisScript=iah/iah.xis\&src=go ogle $\&$ base $=$ LILACS\&lang $=$ p\&nextAction $=\operatorname{lnk} \&$ exprSearch $=5$ 34850\&indexSearch=ID>. Acesso em: 16 mar. 2016.

SOLÍS, Jesús Damián Fernández. Taller Pedagogía del humor: el valor educativo del humor en la Educación Social. CONGRESSO ESTATAL DE EDUCACIÓN SOCIAL, 6., 2012, Valencia. Anais... Disponível em: <http://www.eduso.net/ res/pdf/18/taller7 res 18.pdf>. Acesso em: 1 out. 2015.

SPERBER, Dan; WILSON, Deirdre. Relevance: communication \& cognition. Cambridge, MA: Harvard University, 1986.

SPERBER, Dan; WILSON, Deirdre. Relevance: communication \& cognition. 2. ed. Oxford: Blackwell, 1995. 
YUS, Francisco Ramos. A Decade of Relevance Theory. Journal of Pragmatics, v. 30, p. 305-345, 1998. Disponível em: <http://www.sciencedirect.com/science/article/pii/ S0378216698000150>. Acesso em: 20 fev. 2016.

YUS, Francisco Ramos. Relevance, humour and translation. In: CONFERENCE INTERPRETING FOR RELEVANCE: DISCOURSE AND TRANSLATION, 2010, Poland, Anais... Conference Interpreting for Relevance: Discourse and Translation. Kazimierz Dolny (Poland). 2010. Disponível em: <https://www.researchgate.net/publication/240614420 Relevance_humor_and_translation>. Acesso em: 31 out. 2014.

Recebido: 16 de dezembro de 2016

Aprovado: 27 de fevereiro de 2017

\section{Contato:}

Leila Minatti Andrade <leilaminatti@hotmail.com>

Fábio José Rauen <fabio.rauen@unisul.br> 